\title{
The Gender-Sensitive Social Risk Factors for Internet Addiction in College Undergraduate Students
}

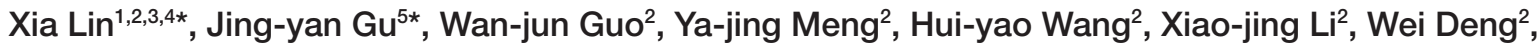 \\ Lian-sheng Zhao ${ }^{2}$, Xiao-hong $\mathrm{Ma}^{2}$, Ming-li Li ${ }^{2}$, Ting Chen ${ }^{2}$, Andy S.K. Cheng ${ }^{6}$, and Tao $\mathrm{Li}^{2} \otimes$ \\ 1Sichuan University-Hong Kong Polytechnic University Institute for Disaster Management and Reconstruction, Chengdu, China \\ ${ }^{2}$ Mental Health Center and Psychiatric Laboratory, Huaxi Brain Research Center, West China Hospital of Sichuan University, Chengdu, China \\ ${ }^{3}$ Department of Clinical Medicine, North Sichuan Medical College, Nanchong, China \\ ${ }^{4}$ Department of Rehabilitation Medicine, Affiliated Hospital of North Sichuan Medical College, Nanchong, China \\ ${ }^{5}$ Department of Psychology, Seattle Pacific University, Seattle, United States \\ ${ }^{6}$ Department of Rehabilitation Sciences, The Hongkong Polytechnic University, Hongkong
}

Objective The current study aims to explore precipitating and social risk factors for internet addiction (IA) in university undergraduate students, and to provide evidence for interventions and the early prevention of IA in different genders.

Methods Four thousand eight hundred and fifty-eight college sophomores completed an online survey on their internet use-related behaviours and social risk factors.

Results We found that more male (8.3\%) than female students (5.4\%) had moderate and severe IA. The main online activity in the moderate and severe IA groups was online gaming in males and online streaming in females. Roommates engaging in similar internetbased entertainment was a risk factor of IA only for males, while not being in a romantic relationship was a risk factor of IA for females only. Infatuation with the internet before college and adjustment problems for college life were shared risk factors for both genders in the mild and moderate IA groups.

Conclusion IA was a common phenomenon in college students with shared and unique precipitating and social risk factors in males and females. The gender-sensitive risk factors for IA warranted earlier and individualized intervention and prevention strategies for IA in this population.

Psychiatry Investig 2021;18(7):636-644

Key Words College students, Internet addiction, Risk factors, Cross-sectional survey, Gender.

\section{INTRODUCTION}

The internet use has grown exponentially during the past two decades. The development of the internet has brought convenience but also problems such as internet addiction (IA). Young ${ }^{1}$ defined IA as losing control over the time spent on the internet. IA could potentially impair academic and occupational function as well as family life. ${ }^{2}$ Although there have been few worldwide studies on the prevalence rate of IA, studies conducted in

\footnotetext{
Received: July 31, 2020 Revised: October 10, 2020

Accepted: April 5, 2021

$\triangle$ Correspondence: Tao Li, MD, PhD

Mental Health Center and Psychiatric Laboratory, Huaxi Brain Research Center, West China Hospital of Sichuan University, No. 28 Dianxin South Street, Chengdu, Sichuan 610041, China

Tel \& Fax: +86-28-85423561, E-mail: litaohx@scu.edu.cn

*These authors contributed equally to this work.

(c) This is an Open Access article distributed under the terms of the Creative Commons Attribution Non-Commercial License (https://creativecommons.org/licenses/by$\mathrm{nc} / 4.0$ ) which permits unrestricted non-commercial use, distribution, and reproduction in any medium, provided the original work is properly cited.
}

different geographic regions suggest that it is a severe problem shared by many countries. ${ }^{3}$ Furthermore, IA is associated with an increased rate of mental health problems. People with heavy IA, such as pathological heavy online game consumers, are likely to develop psychiatric disorders such as depression, social anxiety, and somatic symptoms. ${ }^{4}$

The use of internet-based entertainment differs by gender and geographic region. In the United States, male internet users spend more time on pornography, and females usually spend time on online shopping. ${ }^{5}$ In Europe, male internet users usually play single-player online games, while females spend most of their time on social media. ${ }^{6}$ In Korea, $56.3 \%$ of males play online multiplayer games. ${ }^{7}$ In Hong Kong, 30\% of participants play online games. ${ }^{8}$ Similar to other addictive behaviours, people engage in online entertainment for different reasons. Shiffman and Rathbun ${ }^{9}$ found that people use smoking as a way to cope with negative affect. IA has a clinical presentation similar to that of substance abuse and behavioural abuse, such as 
withdrawal symptoms, tolerance, and craving. ${ }^{10}$ It is worth noting the difference between males and females in addictive behaviours. For example, women were more likely than men to use smoking to cope with negative affect, and a more recent study suggested that men are more likely to report somatic symptoms such as "ill, in pain, or uncomfortable" as triggers for using drugs. ${ }^{11}$

Previous studies suggested that the severity of IA is positively correlated with the amount of time individuals spend on the internet. ${ }^{12}$ However, currently, as technology use skyrockets, internet-based entertainment has become more accessible through smartphones, tablets, and other portable gaming devices (e.g., Nintendo Switch). Consequently, it is more difficult to assess the amount of time and the frequency of use in the traditional manner. ${ }^{13,14}$ In a more recent study, Li et al. ${ }^{15}$ found that sustained time spent on online entertainment tends to increase as IA severity increases. The duration of sustained online entertainment for each episode of internet use might be a better indicator to measure the amount of time of internet use.

Existing studies on risk factors for IA were conducted under the biopsychosocial model. Under this model, the family environment was considered one of the most important social factors. Single-parent, frequent migration, left-behind by parents during childhood, and deceased parents were the most common risk factors. ${ }^{16}$ Boys who experience negative life events are more susceptible to IA. ${ }^{17}$ In addition to the family environment, interpersonal interaction with peers has also been studied. As a platform for sharing similar activities, the internet is a place where adolescents socialize with each other. As a result, the influence of friends could exacerbate adolescents' dependence on the internet. ${ }^{18,19}$

Previous studies have suggested that biological factors, social environment factors (e.g., family, friends, etc.), and other psychological conditions (e.g., depression and social anxiety) together impact individuals' internet use behaviour. ${ }^{20}$ Positive emotions such as happiness, relaxation, confidence, and the sense of achievement that people receive from online activities could serve as moderators that exacerbate IA. ${ }^{21}$ The findings are mixed on the effect of socioeconomic status (SES) and geographic location on IA. Family SES was found to be a predictor of IA. Specifically, children from higher SES families were more vulnerable to IA. ${ }^{22-24}$ Parents' unemployment status and low education levels were also found to be associated with a higher risk of IA.$^{25}$ However, findings are inconsistent, and other studies suggested that parents' education level and family socioeconomic status had no impact on children's IA. ${ }^{17,26}$

In the current study, we explored precipitating and social risk factors for internet addiction (IA) in university undergraduate students in order to provide evidence for interventions and the early prevention of IA in different genders.

\section{METHODS}

\section{Participants}

The investigation was carried out at a comprehensive university in mainland China. All sophomores $(9,367)$ were invited to complete a questionnaire online in November 2013. A total of 4,858 (51.86\%) responded and completed the survey.

\section{Informed consent and confidentiality}

The present study was approved by the Medical Ethics Committee of West China Hospital of Sichuan University (2013, No.185). Online written informed consent was obtained from all participants. Volunteers' confidentiality is in no way breached, and do not use real names, initials, or disclose information that might identify a particular person without informed consent for publication.

\section{Demographics}

The demographics collected in this self-made questionnaire included gender, age of participants, and social risk factors below in this survey.

The social risk factors included number of relocations (migration numbers), childhood trauma experience, if father and/ or mother deceased, infatuation with the internet before college, similar online activities in roommates, a romantic relationship, and unpleasant events on campus. They were defined as follows:

\section{Number of relocations (migration numbers)}

Refers to the number of times the family's permanent residence was relocated. For the convenience of statistical analysis, those who had no relocation experience were assigned a value of 1,1 relocation experience was assigned a value of 2 , 2 relocation experiences were assigned a value of 3 , and 3 or more relocation experiences were assigned a value of 4 .

\section{Childhood trauma experience}

In this study, childhood trauma experience covers neglect and physical abuse before the age of 16 . The Childhood Trauma Questionnaire has been used to evaluate childhood traumatic experience and verified as having good reliability and validity. ${ }^{27,28}$

\section{If father and/or mother deceased \\ Whether parents are deceased.}

\section{Infatuation with the internet before college}

This item was self-reported; infatuation refers to an unreasonable passion for engaging in online activities. 
Similar online activities in roommates

Whether roommates share similar online activities.

With a romantic relationship

Whether the participant was experiencing a romantic relationship or other relationships.

\section{Unpleasant events on campus}

Frequency of suffering unpleasant events after entering the university.

\section{Internet use behaviours}

We recorded the types of online entertainment activities (playing games, browsing information, chatting/posting comments, watching movies/TV series), the duration of sustained online entertainment (sustained engagement with online entertainment in hours for each internet use) and potential triggers for online entertainment activity, including boredom, ${ }^{29,30}$ loneliness/depression/escape. . $^{31-33}$

Young's Internet Addiction Test (IAT) revised edition by Young, a 20-item self-evaluation scale including 6 levels $(0=$ not applicable, $1=$ =almost never, $2=$ occasionally, $3=$ sometimes, $4=$ often, and $5=$ almost), was used in the present study. An IAT score of 50 is commonly considered the cut-off score for IA, which means that individuals who scored 50 or higher were considered to have IA, and those who scored lower than 50 were considered being without IA. ${ }^{34,35}$ The total IAT score can be categorized into four classes of severity (normal: 0 to 30; mild: 31-49; moderate: 50-79; severe: $80-100) .{ }^{36}$ Young's IAT has been translated into different languages and has been verified to have good reliability and validity. ${ }^{37,38}$ The Chinese version was adopted for the present study (Cronbach's alpha: 0.9085). ${ }^{39}$

\section{Statistical analysis}

The participants were separated into three groups (normal group: 0-30, mild IA group: 31-49, moderate and severe IA group: 50-100) based on the scores using the latest revision of the IAT. ${ }^{36}$ SPSS19 was used for data analysis. Two-sample t-tests, chi-squared tests and analysis of variance (ANOVA) were used for continuous variables and categorical variables as appropri- ate. Multiple logistic regression analysis was applied to predict the risk of mild IA, moderate and severe IA. The statistical significance level was set as $\mathrm{p}<0.05$ (two-tailed). The Bonferroni correction and the corrected $\mathrm{p}$-value were used to adjust the $\mathrm{p}$-value while conducting the chi-square analysis.

\section{RESULTS}

\section{Demographics}

A total of 4,858 (51.86\%) sophomores participated in the cross-sectional study. Among these volunteers, $48.93 \%(2,377)$ were males and $51.07 \%(2,481)$ were females. The mean age was $19.58, \mathrm{SD}=0.87$.

\section{Prevalence of IA and IAT mean scores}

The Cronbach's alpha coefficient and Guttman split-half coefficient of IAT were 0.915 and 0.845 , respectively, in the present study.

The prevalence of IA in total was $6.81 \%(331 / 4,858)$. The IA rate was $8.3 \%$ in males $(197 / 2,377)$ and $5.4 \%$ in females (134/ $2,481)$. A higher IA rate in male participants $\left(\chi^{2}=23.115, \mathrm{p}<0.001\right)$ was found in the current study among the 4,858 respondents. Furthermore, there were significant differences in the mean IAT score between the three IA severity groups $(\mathrm{F}=4.344, \mathrm{p}<0.001)$ (Table 1).

\section{Online entertainment activities, triggers, and duration of sustained online entertainment}

The duration of sustained online entertainment in the moderate and severe IA groups (approximately 5 hours) was significantly higher than that in the normal group (approximately 2 hours) for both males and females.

Online gaming is the main online entertainment activity among male students in the moderate and severe IA groups (55.8\%), whereas only $27 \%$ of male students in the normal group play online games.

The main trigger of online entertainment was boredom (male $>60 \%$, female $>70 \%$ ); however, negative affect was the most prevalent trigger of online entertainment activities in the moderate and severe IA groups (male 18.2\%, female 12.7\%, p<0.001).

Table 1. The rate and mean scores of internet addiction $(\mathrm{IA})$ in males and females

\begin{tabular}{|c|c|c|c|c|c|c|c|c|}
\hline \multirow{2}{*}{ IA severity } & \multicolumn{2}{|c|}{ Rate } & \multirow{2}{*}{$\chi^{2}$} & \multirow{2}{*}{$\mathrm{p}$-value } & \multicolumn{2}{|c|}{ IAT scores } & \multirow{2}{*}{$\mathrm{F}$} & \multirow{2}{*}{$\mathrm{p}$-value } \\
\hline & Male & Female & & & Male & Female & & \\
\hline The normal group & $1,272(53.5)$ & $1,461(58.9)$ & 23.115 & $<0.001$ & $23.66 \pm 4.197$ & $24.09 \pm 4.080$ & 4.344 & $<0.001$ \\
\hline The mild IA group & $908(38.2)$ & $886(35.7)$ & & & $37.89 \pm 4.794$ & $37.48 \pm 4.978$ & & \\
\hline The moderate and severe IA group & $197(8.3)$ & $134(5.4)$ & & & $59.91 \pm 8.962$ & $58.15 \pm 9.382$ & & \\
\hline Total & $2,377(100.0)$ & $2,481(100.0)$ & & & $32.1 \pm 11.829$ & $30.71 \pm 10.304$ & & \\
\hline
\end{tabular}

Data are presented as the mean \pm standard deviation or $\mathrm{N}(\%)$. IAT: internet addiction test 
There is no statistically significant difference between the two gender groups in the duration of sustained online entertainment (males 2.72 \pm 3.234 , females 2.58 $\pm 2.983 ; \mathrm{t}=1.527, \mathrm{p}=$ $0.527)$. Compared to the normal group, the moderate and severe groups significantly differed in online entertainment activities, triggers, and duration of sustained online entertainment $(\mathrm{p}<0.001)$ (Table 2).

\section{Social environmental risk factors for internet addiction}

The average number of relocations (migration numbers) was $1.92 \pm 1.046$. The average score on childhood trauma experiences was $1.01 \pm 1.973$. A total of $7.5 \%$ of respondents $(366 / 4,800)$ had a father and/or mother deceased, and $12.5 \%$ of respondents $(607 / 4,857)$ had been infatuated with the internet prior to college. A total of $72.1 \%$ of students $(3,504 / 4,858)$ had roommates with similar online activities; $77.6 \%$ of students $(3,768$ / $4,858)$ did not have a romantic relationship; and 9.4\% $(456 / 4,858)$ suffered unpleasant events on campus.

Students in the moderate and severe IA groups were more likely to report childhood trauma, being infatuated with internet entertainment before college, not in a romantic relationship, and suffering unpleasant events on campus $(\mathrm{p}<0.05)$. Males in the moderate and severe IA groups were more likely to report relocation and father and/or mother deceased.

Additionally, more than $70 \%$ of male and female students re- ported that their roommates engaged in similar online entertainment activities, but the difference between the moderate and severe IA group and the normal group was only marginally significant $(\mathrm{p}=0.051)$ (Table 3$)$.

\section{Multiple logistic regression analysis of risk factors for IA in gender interaction}

The mild, moderate and severe IA as the dependent variables were entered in logistic regression models (the normal group was taken as the reference variable). Independent variables, including if father and/or mother deceased, infatuating with network before college, unpleasant events on campus, with a romantic relationship, similar online activities in roommates, childhood trauma experiences, migration times, were entered in logistic regression models by stepwise analysis after having an interaction for male and female, respectively. The model has an acceptable goodness of fit $\left(\chi^{2}=6,013.952, p<0.001\right)$. Infatuation with the internet before college and unpleasant events on campus were common risk factors for mild and moderate IA in both gender groups (all $\mathrm{p}<0.001$ ). In particular, infatuation with the internet before college was the strongest predictor of moderate and severe IA (male: $\mathrm{OR}=5.739,95 \% \mathrm{CI}$ : 3.862-8.529; female: $\mathrm{OR}=12.239$, 95\% CI: 7.523-19.911).

Roommates engaging in similar online activities displayed a significant effect on male students' IA (mild IA group, $\mathrm{p}<0.001$, $\mathrm{OR}=1.535$, 95\% CI: 1.249-1.886; moderate and severe IA group,

Table 2. Sustained online entertainment duration, online entertainment activities and triggers in the moderate and severe IA groups compared with the normal group

\begin{tabular}{|c|c|c|c|c|c|c|c|c|}
\hline & \multicolumn{2}{|c|}{ Male } & \multirow{3}{*}{$\chi^{2} / \mathrm{t}$} & \multirow{3}{*}{ p-value } & \multicolumn{2}{|c|}{ Female } & \multirow{3}{*}{$\chi^{2} / \mathrm{t}$} & \multirow{3}{*}{$\mathrm{p}$-value } \\
\hline & $\begin{array}{l}\text { Normal } \\
\text { group }\end{array}$ & $\begin{array}{c}\text { The } \\
\text { moderate and } \\
\text { severe group }\end{array}$ & & & $\begin{array}{l}\text { Normal } \\
\text { group }\end{array}$ & $\begin{array}{c}\text { The } \\
\text { moderate and } \\
\text { severe group }\end{array}$ & & \\
\hline & $\mathrm{N}=1,272$ & $\mathrm{~N}=197$ & & & $\mathrm{~N}=1,461$ & $\mathrm{~N}=134$ & & \\
\hline $\begin{array}{l}\text { The sustained online entertainment duration } \\
\text { (hours/every time) }\end{array}$ & $2.14 \pm 2.174$ & $4.94 \pm 7.725$ & -5.043 & $<0.001$ & $2.20 \pm 2.140$ & $4.76 \pm 9.434$ & -3.11 & 0.002 \\
\hline Online entertainment activities & & & 78.397 & $<0.001$ & & & 27.115 & $<0.001$ \\
\hline Playing games & $343(27.0)$ & $110(55.8)$ & & & $30(2.1)$ & $8(6.0)$ & & \\
\hline Browsing information & $223(17.5)$ & $18(9.1)$ & & & $170(11.6)$ & $9(6.7)$ & & \\
\hline Chatting/post bar & $147(11.6)$ & $28(14.2)$ & & & $213(14.6)$ & $23(17.2)$ & & \\
\hline Watching movies/TV series & $478(37.6)$ & $31(15.7)$ & & & $923(63.2)$ & $69(51.5)$ & & \\
\hline Others & $81(6.4)$ & $10(5.1)$ & & & $125(8.6)$ & $25(18.7)$ & & \\
\hline Online entertainment activity triggers & & & 54.6 & $<0.001$ & & & 48.506 & $<0.001$ \\
\hline Boring & $864(67.9)$ & $125(63.5)$ & & & $1,118(76.5)$ & $98(73.1)$ & & \\
\hline Lonely/depressed/escaping & $98(7.7)$ & $46(23.4)$ & & & $87(6.0)$ & $28(20.9)$ & & \\
\hline Friends' invitation & $193(15.2)$ & $21(10.7)$ & & & $76(5.2)$ & $1(0.7)$ & & \\
\hline Others & $117(9.2)$ & $5(2.5)$ & & & $180(12.3)$ & $7(5.2)$ & & \\
\hline
\end{tabular}

Data are presented as the mean \pm standard deviation or $\mathrm{N}(\%) .1$ ) (\%) is the percentage in column, 2) Alpha level was adjusted using Bonferroni correction. IA: internet addiction 
Table 3. Migration times, childhood trauma experiences, parents, infatuating with the internet before college, roommates, with a romantic relationship, unpleasant events on campus between the moderate and severe group and normal group

\begin{tabular}{|c|c|c|c|c|c|c|c|c|}
\hline \multirow{3}{*}{ Social factors } & \multicolumn{2}{|c|}{ Male } & \multirow{3}{*}{$t / \chi^{2}$} & \multirow{3}{*}{ p-value } & \multicolumn{2}{|c|}{ Female } & \multirow{3}{*}{$t / \chi^{2}$} & \multirow{3}{*}{ p-value } \\
\hline & $\begin{array}{c}\text { The normal } \\
\text { group }\end{array}$ & $\begin{array}{c}\text { The moderate } \\
\text { and severe IA } \\
\text { group }\end{array}$ & & & $\begin{array}{l}\text { The normal } \\
\text { group }\end{array}$ & $\begin{array}{c}\text { The moderate } \\
\text { and severe IA } \\
\text { group }\end{array}$ & & \\
\hline & $\mathrm{N}=1,272$ & $\mathrm{~N}=197$ & & & $\mathrm{~N}=1,461$ & $\mathrm{~N}=134$ & & \\
\hline Migration times & $1.826 \pm 1.151$ & $2.26 \pm 1.505$ & -3.864 & $<0.001$ & $1.97 \pm 1.150$ & $2.04 \pm 1.300$ & -0.681 & 0.496 \\
\hline Childhood trauma experiences & $7.06 \pm 2.439$ & $7.88 \pm 2.533$ & -4.484 & $<0.001$ & $6.64 \pm 1.527$ & $7.20 \pm 1.679$ & -3.386 & 0.001 \\
\hline \multicolumn{9}{|l|}{ If father and/or mother deceased } \\
\hline No & $1,174(93.5)$ & $166(86.0)$ & 13.387 & $<0.001$ & $1,357(93.8)$ & $118(89.4)$ & 3.783 & 0.052 \\
\hline Yes & $82(6.5)$ & $27(14.0)$ & & & $90(6.2)$ & $14(10.6)$ & & \\
\hline \multicolumn{9}{|l|}{ Infatuating with the internet before college } \\
\hline No & $1,169(91.9)$ & $120(60.9)$ & 152.356 & $<0.001$ & $1,409(96.4)$ & $95(70.9)$ & 148.884 & $<0.001$ \\
\hline Yes & $103(8.1)$ & $77(39.1)$ & & & $52(3.6)$ & $39(29.1)$ & & \\
\hline Similar online activities in roommates & & & & & & & 0.009 & 0.924 \\
\hline No & $404(31.8)$ & $49(24.9)$ & 3.795 & 0.051 & $420(28.7)$ & $38(28.4)$ & & \\
\hline Yes & $868(68.2)$ & $148(75.1)$ & & & $1,041(71.3)$ & $96(71.6)$ & & \\
\hline \multicolumn{9}{|l|}{ With a romantic relationship } \\
\hline No & $969(76.2)$ & $165(83.8)$ & 5.563 & 0.018 & $1,096(75.0)$ & $114(85.1)$ & 6.780 & 0.009 \\
\hline Others & $303(23.8)$ & $32(16.2)$ & & & $365(25.0)$ & $20(14.9)$ & & \\
\hline \multicolumn{9}{|l|}{ Unpleasant events in campus } \\
\hline Rarely & $543(42.7)$ & $33(16.8)$ & & & $515(35.2)$ & $14(10.4)$ & & \\
\hline Occasionally & $396(31.1)$ & $31(15.7)$ & 147.518 & $<0.001$ & $579(39.6)$ & $38(28.4)$ & 111.463 & $<0.001$ \\
\hline Sometimes & $231(18.2)$ & $75(38.1)$ & & & $292(20.0)$ & $49(36.6)$ & & \\
\hline Plenty & $102(8.0)$ & $58(29.4)$ & & & $75(5.1)$ & $33(24.6)$ & & \\
\hline
\end{tabular}

Data are presented as the mean \pm standard deviation or $\mathrm{N}(\%) .1$ ) (\%) is the column percentage, 2) The intergroup difference test of frequency was corrected by Bonferroni correction, 3 ) The corrected p-value of comparison between groups of the mean is: $0.05 \div 3$ (factor numbers) $=$ 0.017 , while $\mathrm{p}$-value $<0.017$ means there is a significant difference between groups. IA: internet addiction

$\mathrm{p}=0.002, \mathrm{OR}=1.829,95 \% \mathrm{CI}: 1.240-2.698)$. In contrast, female students addicted to internet entertainment activities were influenced by the absence of romantic relationships (mild IA group, $\mathrm{p}=0.019$, $\mathrm{OR}=0.768,95 \% \mathrm{CI}$ : $0.616-0.958$; moderate and severe IA group, $\mathrm{p}=0.006, \mathrm{OR}=0.479,95 \% \mathrm{CI}$ : $0.284^{-}$ 0.809) (Table 4).

\section{DISCUSSION}

In the present study, we found that more male than female students had moderate and severe IA. In the moderate and severe IA group, both male and female students tended to uninterruptedly use the internet for more than 5 hours once they started. The main online activity for the male students in the moderate and severe IA groups was online gaming, while female students with moderate or severe IA preferred to online streaming (e.g., watching movies and dramas). Boredom was the most prominent trigger for using internet-based entertainment. However, internet use triggered by negative emotion was more likely to develop into moderate or severe IA. Infatuation with the internet before college and adjustment problems for college life were shared risk factors for both gender groups in the mild and moderate IA groups. Roommates engaging in similar internet-based entertainment was a risk factor only for IA in male students, and not being in a romantic relationship was only a risk factor for IA in female students. Relocation, the death of one or both parents, and childhood traumatic experience only affected mild IA.

\section{Type of internet use and different effects of IA in different genders}

The main type of internet-based entertainment was different between male and female participants. Similar to previous research, our study found that online gaming is the main type of IA for male students. ${ }^{4}$ For female students in the moderate and severe IA group, 51.5\% chose to use online streaming services as their main internet-based entertainment. This is possibly due to the relatively easy accessibility of online streaming 
Table 4. Multivariate logistic regression analysis of gender interaction risk factors of Internet addiction

\begin{tabular}{|c|c|c|c|c|c|c|c|c|c|c|}
\hline \multirow{3}{*}{ Gender interaction risk factors } & \multicolumn{5}{|c|}{$\begin{array}{l}\text { The mild IA group } \\
\text { (IAT: } 31-49 \text { points) }\end{array}$} & \multicolumn{5}{|c|}{$\begin{array}{l}\text { The moderate and severe IA group } \\
\text { (IAT: } 50-100 \text { points) }\end{array}$} \\
\hline & \multirow{2}{*}{$\mathrm{B}$} & \multirow{2}{*}{ p-value } & \multirow{2}{*}{ OR } & \multicolumn{2}{|c|}{$95 \% \mathrm{CI}$} & \multirow{2}{*}{$\mathrm{B}$} & \multirow{2}{*}{ p-value } & \multirow{2}{*}{ OR } & \multicolumn{2}{|c|}{$95 \% \mathrm{CI}$} \\
\hline & & & & Low & High & & & & Low & High \\
\hline Intercept & -3.955 & $<0.001$ & & & & -8.261 & $<0.001$ & & & \\
\hline \multicolumn{11}{|l|}{ Male } \\
\hline If father and/or mother deceased & 0.350 & 0.033 & 1.420 & 1.029 & 1.958 & 0.497 & 0.061 & 1.644 & 0.978 & 2.765 \\
\hline Infatuating with network before college & 1.159 & $<0.001$ & 3.186 & 2.440 & 4.158 & 1.747 & $<0.001$ & 5.739 & 3.862 & 8.529 \\
\hline Unpleasant events on campus & 0.276 & $<0.001$ & 1.318 & 1.187 & 1.463 & 0.547 & $<0.001$ & 1.728 & 1.432 & 2.087 \\
\hline With a romantic relationship & -0.204 & 0.081 & 0.815 & 0.648 & 1.026 & -0.417 & 0.071 & 0.659 & 0.419 & 1.036 \\
\hline Similar online activities in roommates & 0.428 & $<0.001$ & 1.535 & 1.249 & 1.886 & 0.604 & 0.002 & 1.829 & 1.240 & 2.698 \\
\hline Childhood trauma experiences & -0.013 & 0.519 & 0.987 & 0.947 & 1.028 & 0.040 & 0.190 & 1.041 & 0.980 & 1.106 \\
\hline Migration times & 0.105 & 0.026 & 1.110 & 1.013 & 1.218 & 0.147 & 0.071 & 1.158 & 0.988 & 1.358 \\
\hline \multicolumn{11}{|l|}{ Female } \\
\hline If father and/or mother deceased & 0.076 & 0.665 & 1.079 & 0.766 & 1.520 & 0.667 & 0.033 & 1.948 & 1.056 & 3.592 \\
\hline Infatuating with network before college & 1.421 & $<0.001$ & 4.143 & 2.937 & 5.844 & 2.505 & $<0.001$ & 12.239 & 7.523 & 19.911 \\
\hline Unpleasant events in campus & 0.264 & $<0.001$ & 1.302 & 1.162 & 1.458 & 0.489 & $<0.001$ & 1.630 & 1.294 & 2.053 \\
\hline With a romantic relationship & -0.264 & 0.019 & 0.768 & 0.616 & 0.958 & -0.736 & 0.006 & 0.479 & 0.284 & 0.809 \\
\hline Similar online activities in roommates & 0.335 & 0.001 & 1.398 & 1.143 & 1.708 & 0.388 & 0.064 & 1.473 & 0.978 & 2.221 \\
\hline Childhood trauma experiences & 0.053 & 0.017 & 1.054 & 1.010 & 1.101 & 0.058 & 0.176 & 1.060 & 0.974 & 1.154 \\
\hline Migration times & 0.073 & 0.107 & 1.076 & 0.984 & 1.176 & -0.064 & 0.509 & 0.938 & 0.776 & 1.134 \\
\hline
\end{tabular}

$\mathrm{p}<0.05$ was considered statistically significant; Unpleasant events in campus: $1=$ rarely, $2=$ occasionally, $3=$ sometimes, $4=$ plenty; Similar online activities in roommates: $1=$ no, $2=$ yes; With a romantic relationship: $1=$ no, $2=$ others; Infatuating with the internet before college: $1=$ no, $2=y e s$; If father and/or mother deceased: $1=$ no, $2=y e s ;$ Migration times: $1=0,2=1,3=2,4=3$ and more. IA: internet addiction, IAT: internet addiction test, B: regression coefficient, OR: odds ratio, CI: confidence interval

services. And it is also a risk factor for IA in female students, suggesting that research on female college students' IA should focus on this subtype. The different choice of internet-based entertainment between male and female students may be due to their unique needs and goals in using the internet.

It was suggested that the online activities of IA might be gender-sensitive, and the risk factors for IA might have some difference between males and females. ${ }^{40,41} \mathrm{~A}$ number of studies explored the effects of IA by gender and reported different results. For instance, in 2011, Wang et al. ${ }^{42}$ studied 14,296 high school students and found that $12.2 \%$ of them were problematic internet users (PIUs), While they did not find gender difference between PIUs and non-PIUs by using generalized mixedmodel regression analysis. Regards to the means of IA, female adolescents seem to be prone to a higher risk for smartphone use addiction than males, ${ }^{40}$ though an independent study revealed opposite conclusion. ${ }^{41}$ Teng et al. ${ }^{43}$ found lower self-esteem and poorer social support as the important risk factors for IA, and showed different correlations in males and females. Kim et al. ${ }^{44}$ reported that the novelty-seeking, self-transcendence, and daily time spent gaming predicted IA in males significantly. Notably, males with IA also showed more serious so- cial problems than females. ${ }^{45}$

\section{Duration of sustained online entertainment}

The duration of sustained online entertainment was used as an indicator of prolonged internet use for IA. It varied from 2 hours in the normal group to 5 hours in the moderate and severe IA groups. Previous studies usually use "how many hours per day" and "how many days per week" to assess the severity of IA. ${ }^{13,14}$ Wei et al. ${ }^{4}$ suggest that women tend to have shorter duration of sustained online entertainment, which is contradictory to our findings. Our study found no statistically significant difference between gender groups, which suggests that it could potentially serve as a universal indicator of the severity of IA for both men and women.

\section{Triggers of internet-based entertainment}

Boredom, stress, and negative affect were common triggers of massive internet use. ${ }^{46,47}$ Boredom was the main trigger of mild IA. Participants in the moderate and severe IA group reported a significantly higher incidence of negative affect-triggered internet use than boredom-triggered use. This suggests that online entertainment serves as a coping mechanism for 
individuals with moderate to severe IA. Female students rarely report invitation from friends as a trigger for online entertainment, while it is the second most reported trigger from male students.

\section{Risk factors for IA}

History of using the internet (infatuation with the internet) is considered a predictor of IA. Most individuals with internet game addiction reported having their first contact with online games in primary school and with internet overuse in middle school. ${ }^{15}$ the time point of first contact might influence the severity of IA. ${ }^{4}$ Our study yields a similar finding that experience with online games during early adolescence has an important impact on internet game addiction. Additionally, infatuation with the internet before college and adjustment issues at the beginning of college are common risk factors across gender groups.

IA could be a result of interaction between genetic and environmental factors. First-degree relatives of pathological gamblers showed significantly higher incidences of addictive behaviours compared to control groups. ${ }^{48,49} \mathrm{~A}$ twin study discovered that IA is 20 to 48 percent influenced by genetic factors ${ }^{50,51}$ and over 50 percent by environmental factors. ${ }^{50}$ The current study found that infatuation with the internet before college and early encounters with the internet at a young age are prominent risk factors for IA. This suggests that genetic vulnerabilities combined with the influence of the family environment may play an important role in early contact with online entertainment and IA in childhood or adolescence.

\section{Clinical implication}

Since the current study found that boredom is a common trigger of internet use for college students, it is important to develop intervention strategies to target this problem. In China, high school students commonly spend an enormous amount of time preparing for college entrance exams. After the exam, students who were successfully admitted by colleges have much more free time to be spend by their own planning. Helping students to engage in meaningful campus activities might relieve their boredom, and reduce the likelihood of students being addicted to the internet. Additionally, schools should pay close attention to the differences in triggering events between gender groups and provide interventions accordingly. Furthermore, online entertainments were potentially served as a coping mechanism for negative emotion, discussing emotional regulation and skills dealing with stress events with students in their earlier college life could be of beneficial.

\section{Limitations}

There were a number of limitations in present study. Firstly, the response rate in the cross-sectional study was only $51.86 \%$, which might result in sampling bias. Secondly, since our study is conducted on college undergraduate students, the results may have the limitation of being generalizable to the broader population. Further studies should be done to validate our findings.

\section{Acknowledgments}

This work was partly funded by National Nature Science Foundation of China Key Project (81630030 and 81920108018); the Department of Science and Technology of Sichuan provincial government (2019YFS0535); and the 1.3.5 Project for disciplines of excellence, West China Hospital of Sichuan University (ZY2016103, ZY2016203 and ZYGD20004); Education Department of Sichuan Province, China (11SB142); Sichuan Provincial Health and Family Planning Commission, China (17PJ077) and the cooperation program of North Sichuan Medical College and Nanchong City, China (18SXHZ0556).

\section{Conflicts of Interest}

The authors have no potential conflicts of interest to disclose.

\section{Author Contributions}

Conceptualization: Tao Li, Xia Lin, Andy S.K. Cheng. Data curation: Wan-jun Guo, Ya-jing Meng. Formal analysis: Ming-li Li. Funding acquisition: Tao Li, Xia Lin. Investigation: all authors. Methodology: all authors. Project administration: Hui-yao Wang, Xiao-jing Li. Resources: all authors. Software: Wei Deng, Lian-sheng Zhao. Supervision: Xiao-hong Ma. Validation: Hui-yao Wang, Xiao-jing Li. Visualization: Ting Chen. Writingoriginal draft: Jing-yan Gu, Xia Lin. Writing_review \& editing: all authors.

\section{ORCID iDs}

$\begin{array}{ll}\text { Xia Lin } & \text { https://orcid.org/0000-0001-6922-6452 } \\ \text { Jing-yan Gu } & \text { https://orcid.org/0000-0001-7799-0610 } \\ \text { Wan-jun Guo } & \text { https://orcid.org/0000-0002-0517-3352 } \\ \text { Ya-jing Meng } & \text { https://orcid.org/0000-0002-9688-0000 } \\ \text { Hui-yao Wang } & \text { https://orcid.org/0000-0001-8417-0848 } \\ \text { Xiao-jing Li } & \text { https://orcid.org/0000-0003-4129-7149 } \\ \text { Wei Deng } & \text { https://orcid.org/0000-0001-5937-9877 } \\ \text { Lian-sheng Zhao } & \text { https://orcid.org/0000-0002-3008-5135 } \\ \text { Xiao-hong Ma } & \text { https://orcid.org/0000-0003-2627-9946 } \\ \text { Ming-li Li } & \text { https://orcid.org/0000-0002-0818-4460 } \\ \text { Ting Chen } & \text { https://orcid.org/0000-0003-3865-8484 } \\ \text { Andy S.K. Cheng } & \text { https://orcid.org/0000-0001-7503-5273 } \\ \text { Tao Li } & \text { https://orcid.org/0000-0003-3831-901X }\end{array}$

\section{REFERENCES}

1. Young KS. Internet Addiction: the emergence of a new clinical disorder. Cyberpsychol Behav 1998;1:237-244.

2. Young KS. Internet Addiction: Symptoms, Evaluation and Treatment. In: VandeCreek L, Jackson TL, Editors. Innovations in Clinical Practice: A Source Book, 1st Edition. Sarasota, FL: Professional Resource Exchange Inc; 1999, p.19-31.

3. Goel D, Subramanyam A, Kamath R. A study on the prevalence of internet addiction and its association with psychopathology in Indian adolescents. Indian J Psychiatry 2013;55:140-143.

4. Wei HT, Chen MH, Huang PC, Bai YM. The association between online gaming, social phobia, and depression: an internet survey. BMC Psychiatry 2012;12:92.

5. Young KS. Treatment outcomes using CBT-IA with Internet-addicted patients. J Behav Addict 2013;2:209-215.

6. Durkee T, Kaess M, Carli V, Parzer P, Wasserman C, Floderus B, et al. Prevalence of pathological internet use among adolescents in Europe: demographic and social factors. Addiction 2012;107:2210-2222. 
7. Ha YM, Hwang WJ. Gender differences in internet addiction associated with psychological health indicators among adolescents using a National Web-based Survey. Int J Ment Health Addict 2014;12:660-669.

8. Wang CW, Ho RT, Chan CL, Tse S. Exploring personality characteristics of Chinese adolescents with internet-related addictive behaviors: trait differences for gaming addiction and social networking addiction. Addict Behav 2015;42:32-35.

9. Shiffman S, Rathbun SL. Point process analyses of variations in smoking rate by setting, mood, gender, and dependence. Psychol Addict Behav 2011;25:501-510.

10. Miyata H. Reconsideration of nicotine and other substance dependence: a clue from dependence-related mentation including reward, motivation, learning, delusion and hallucination toward understanding the concept of non-substance-related addiction. Nihon Shinkei Seishin Yakurigaku Zasshi 2013;33:191-197.

11. Kennedy AP, Epstein DH, Phillips KA, Preston KL. Sex differences in cocaine/heroin users: drug-use triggers and craving in daily life. Drug Alcohol Depend 2013;132:29-37.

12. Ding WN, Sun JH, Sun YW, Zhou Y, Li L, Xu JR, et al. Altered default network resting-state functional connectivity in adolescents with Internet gaming addiction. PLos One 2013;8:e59902.

13. Morioka H, Itani O, Osaki Y, Higuchi S, Jike M, Kaneita Y, et al. Association between smoking and problematic internet use among Japanese adolescents: large-scale nationwide epidemiological study. Cyberpsychol Behav Soc Netw 2016;19:557-561.

14. Baggio S, Dupuis M, Studer J, Spilka S, Daeppen JB, Simon O, et al. Reframing video gaming and internet use addiction: empirical crossnational comparison of heavy use over time and addiction scales among young users. Addiction 2016;111:513-522.

15. Li W, O’Brien JE, Snyder SM, Howard MO. Characteristics of internet addiction/pathological internet use in U.S. university students: a qualitative-method investigation. PLoS One 2015;10:e0117372.

16. Guo J, Chen L, Wang X, Liu Y, Chui CH, He H, et al. The relationship between Internet addiction and depression among migrant children and left-behind children in China. Cyberpsychol Behav Soc Netw 2012; 15:585-590.

17. Tang J, Yu Y, Du Y, Ma Y, Zhang D, Wang J. Prevalence of internet addiction and its association with stressful life events and psychological symptoms among adolescent internet users. Addict Behav 2014;39: 744-747.

18. Meena PS, Mittal PK, Solanki RK. Problematic use of social networking sites among urban school going teenagers. Ind Psychiatry J 2012; 21:94-97.

19. Gainsbury SM, King DL, Russell AM, Delfabbro P. Who pays to play freemium games? The profiles and motivations of players who make purchases within social casino games. J Behav Addict 2016;5:221-230.

20. Griffiths M. A 'components' model of addiction within a biopsychosocial framework. J Subst Use 2009;10:191-197.

21. Lachmann B, Sariyska R, Kannen C, Cooper A, Montag C. Life satisfaction and problematic Internet use: evidence for gender specific effects. Psychiatry Res 2016;238:363-367.

22. Lee CS, McKenzie K. Socioeconomic and geographic inequalities of internet addiction in Korean adolescents. Psychiatry Investig 2015;12: 559-562.

23. Santos V, Nardi AE, King AL. Treatment of internet addiction in patient with panic disorder and obsessive compulsive disorder: a case report. CNS Neurol Disord Drug Targets 2015;14:341-344.

24. Xu J, Shen LX, Yan CH, Hu H, Yang F, Wang L, et al. Parent-adolescent interaction and risk of adolescent internet addiction: a populationbased study in Shanghai. BMC Psychiatry 2014;14:112.

25. Petry NM, Rehbein F, Gentile DA, Lemmens JS, Rumpf HJ, Mößle T, et al. An international consensus for assessing internet gaming disorder using the new DSM-5 approach. Addiction 2014;109:1399-1406.

26. Ghamari F, Mohammadbeigi A, Mohammadsalehi N, Hashiani AA. Internet addiction and modeling its risk factors in medical students, iran. Indian J Psychol Med 2011;33:158-162.

27. Green JG, McLaughlin KA, Berglund PA, Gruber MJ, Sampson NA, Zaslavsky AM, et al. Childhood adversities and adult psychiatric disorders in the national comorbidity survey replication I: associations with first onset of DSM-IV disorders. Arch Gen Psychiatry 2010;67: 113-123.

28. McLaughlin KA, Green JG, Gruber MJ, Sampson NA, Zaslavsky AM, Kessler RC. Childhood adversities and adult psychiatric disorders in the national comorbidity survey replication II: associations with persistence of DSM-IV disorders. Arch Gen Psychiatry 2010;67:124-132.

29. Nalwa K, Anand AP. Internet addiction in students: a cause of concern. Cyberpsychol Behav 2003;6:653-656.

30. Gür K, Yurt S, Bulduk S, Atagöz S. Internet addiction and physical and psychosocial behavior problems among rural secondary school students. Nurs Health Sci 2015;17:331-338.

31. Yen CF, Chou WJ, Liu TL, Yang P, Hu HF. The association of Internet addiction symptoms with anxiety, depression and self-esteem among adolescents with attention-deficit/hyperactivity disorder. Compr Psychiatry 2014;55:1601-1608.

32. Zanetta Dauriat F, Zermatten A, Billieux J, Thorens G, Bondolfi G, Zullino D, et al. Motivations to play specifically predict excessive involvement in massively multiplayer online role-playing games: evidence from an online survey. Eur Addict Res 2011;17:185-189.

33. Engelberg E, Sjöberg L. Internet use, social skills, and adjustment. Cyberpsychol Behav 2004;7:41-47.

34. Ni X, Yan H, Chen S, Liu Z. Factors influencing internet addiction in a sample of freshmen university students in China. Cyberpsychol Behav 2009;12:327-330.

35. Poli R, Agrimi E. Internet addiction disorder: prevalence in an Italian student population. Nord J Psychiatry 2012;66:55-59.

36. Young KS. Internet Addiction--A Handbook and Guide to Evaluation and Treatment. Hoboken, New Jersey: John Wiley \& Sons, Inc.; 2011.

37. Pontes HM, Patrão IM, Griffiths MD. Portuguese validation of the Internet Addiction Test: an empirical study. J Behav Addict 2014;3:107114.

38. Lu X, Yeo KJ. Psychometric properties of the Internet Addiction Test in a sample of Malaysian undergraduate students. Psicología Educativa 2015;21:17-25.

39. Cao JQ, Yang JW, Yang J, Yao DZ, Zhou YQ. Study on reliability and validity of Internet addiction impairment scale. Chin Gen Med 2010; 3903-3905.

40. Fischer-Grote L, Kothgassner OD, Felnhofer A. Risk factors for problematic smartphone use in children and adolescents: a review of existing literature. Neuropsychiatr 2019;33:179-190.

41. Csibi S, Demetrovics Z, Szabó A. [Validation of the Brief Addiction to Smartphone Scale (BASS) and the Hungarian Smartphone Deprivation Inventory (HSDI) in adult sample]. Psychiatr Hung 2019;34:4-10.

42. Wang H, Zhou X, Lu C, Wu J, Deng X, Hong L. Problematic Internet Use in high school students in Guangdong Province, China. PLoS One 2011;6:e19660.

43. Teng Z, Pontes HM, Nie Q, Xiang G, Griffiths MD, Guo C. Internet gaming disorder and psychosocial well-being: a longitudinal study of older-aged adolescents and emerging adults. Addict Behav 2020;110: 106530.

44. Kim YJ, Roh D, Lee SK, Canan F, Potenza MN. Factors statistically predicting at-risk/problematic internet use in a sample of young adolescent boys and girls in South Korea. Front Psychiatry 2018;9:351.

45. Černja I, Vejmelka L, Rajter M. Internet addiction test: croatian preliminary study. BMC Psychiatry 2019;19:388.

46. Dong G, Lu Q, Zhou H, Zhao X. Precursor or sequela: pathological disorders in people with Internet addiction disorder. PLoS One 2011;6: e14703.

47. Wang WC. Exploring the relationship among free-time management, leisure boredom, and internet addiction in undergraduates in Taiwan. Psychol Rep 2019;122:1651-1665. 
48. Black DW, Monahan PO, Temkit M, Shaw M. A family study of pathological gambling. Psychiatry Res 2006;141:295-303.

49. Black DW, Coryell W, Crowe R, Shaw M, McCormick B, Allen J. The relationship of DSM-IV pathological gambling to compulsive buying and other possible spectrum disorders: results from the Iowa PG family study. Psychiatry Res 2015;226:273-276.
50. Vink JM. Genetics of addiction: future focus on gene $\mathrm{x}$ environment interaction? J Stud Alcohol Drugs 2016;77:684-687.

51. Hahn E, Reuter M, Spinath FM, Montag C. Internet addiction and its facets: the role of genetics and the relation to self-directedness. Addict Behav 2017;65:137-146. 